\title{
Use of Deep Eutectic Solvent-based Air-assisted Emulsification Liquid-liquid Microextraction of Palladium and Determination by Flame Atomic Absorption Spectrometry in Water and Environmental Samples
}

\author{
Abdul Haleem Panhwar ${ }^{a, b}$, Mustafa Tuzen ${ }^{a, *}$, and Tasneem Gul Kazi ${ }^{b}$ \\ a Tokat Gaziosmanpasa University, Faculty of Science and Arts, Chemistry Department, \\ 60250 Tokat, Turkey \\ b National Centre of Excellence in Analytical Chemistry, University of Sindh, Jamshoro 76080, Pakistan
}

Palladium II is a metal of economic importance since it has many applications for use in chemical catalysts and for electrical appliances $(1,2)$. Some compounds of Pd(II) have been recognized as hazardous material to human beings causing rhinovirus, conjunctivitis allergy, asthma, and other severe health complications (3). The noble metals are used in the catalytic converter to reduce air pollution. The compounds of $\mathrm{Pd}(\mathrm{II})$ can be released into the aquatic environments, on matter of solid suspen-ded air, sediments, soils and road dust (4). Thus, Pd(II) monitoring in industrial and environmental samples is important for the protection of human health $(5,6)$.

However, due to the inadequate sensitivity of instruments, the measurement of metal ions at very low concentrations is difficult (7). To overcome this drawback, different enrichment procedures have been used for the extraction and enrichment of Pd(II) such as liquid-liquid extraction (8), solid phase extraction (9), cloud point extraction (10), flow injection extraction (11), and dispersive liquid-liquid microextraction (12). These procedures have limitations and require long extraction times, high volumes of dispersive and extraction solvents, and cause secondary waste (13).

*Corresponding author.

E-mail: mustafa.tuzen@gop.ed.tr

Tel: +903562521585

\section{ABSTRACT}

A simple, efficient, green, and sensitive enrichment method is presented for the determination of palladium (II) in water and environmental samples using deep eutectic solvent-based airassisted emulsification liquidliquid microextraction (DES-AAELLME) and flame atomic absorption spectrometry for analysis. In this procedure, the $\mathrm{Pd}$ (II) extraction was obtained using 2-hydroxy3-methoxybenzaldehyde thiosemicarbazone (HMBATSC) a complexing agent, tetrahydrofuran (THF) and choline chloridephenol as emulsifier, and extraction solvents, respectively. The various analytical parameters, including type and molar ratio of the deep eutectic solvent, $\mathrm{pH}$, amount of ligand, and pulling and pushing of the syringe, were studied and optimized. In the experiments, the optimal conditions, analytical characteristics of the investigated method and the limit of detection $\left(1.2 \mu \mathrm{g} \mathrm{L}^{-1}\right)$, relative standard deviation (3.6\%), linear range ( 4 to $500 \mu \mathrm{g} \mathrm{L}^{-1}$ ), and preconcentration factor (70) were measured.

The accuracy of the DES-AAELLME method was confirmed with a certified reference material (NIST SRM 2557 Catalyst). The developed method was satisfactorily applied to real water samples with the standard addition method as well as acid-digested environmental samples.
Preconcentration methods generally require toxic organic solvents for extraction of the hydrophobic complexes of analytes; however, use of environmentally friendly and non-hazardous green solvents can decrease hazardous waste (14-16).

Several techniques such as inductively coupled plasma atomic emission spectrometry (ICP-AES) (17), graphite furnace atomic absorption spectrometry (18), flame atomic absorption spectrometry (19), ultraviolet-visible spectrometry (20), neutron activation analysis (21), and inductively coupled plasma mass spectrometry (22) have been used for the measurement of Pd(II). The direct measurement by these analytical instruments is limited owing to interferences produced by environmental matrices. To overcome complex matrix interferences and obtain quantitative low concentrations of Pd(II), an enrichment step, such as deep eutectic liquid-liquid microextraction (DLLME), is required.

In this study, a DLLME procedure, specifically as air-assisted dispersive liquid-liquid microextraction (AALLME), is presented in which an extracting solvent was mixed into a standard or sample solution. The mixture was repeatedly pulled and pushed via a syringe and injected into a tube (23). The formation of tiny droplets in AALLME is of great advantage over other reported methods. These droplets consider- 
ably increase the surface contact amongst the molecules of both immiscible liquids. The interaction between the extraction solvent and the analyte is enhanced, and the turbidity of the solution increases. Therefore, a greater analyte recovery is obtained in a very short time.

To our knowledge, no work has been reported in the literature about the grouping of AA-ELLME and water/DES for the enrichment of Pd(II). In the present study, DESAA-ELLME, a new green technique, is presented where the formation of a stable single-phase (DES/water) solution has been achieved by adding two discrete components of hydrogen band donor (HBD). The droplets of DES were dispersed into a mixture of standards and samples by frequent cycling of uptake and discharge of the extraction solvent and aqueous sample in a centrifuge tube with a commercial syringe $(10 \mathrm{~mL})$. The separation of DES was performed in the aqueous solution by mixing an aprotic solvent. The DES-AA-ELLME method was applied to water and environmental samples for analysis by FAAS.

\section{EXPERIMENTAL}

\section{Instrumentation}

A model AAnalyst ${ }^{\mathrm{TM}} 700$ FAAS was used (PerkinElmer, Inc., Shelton, CT, USA), equipped with a deuterium background correction system and an air-acetylene burner, for the determination of Pd(II). The analysis was performed using the following operating conditions: analytical wavelength of $244.8 \mathrm{~nm}$, spectral bandwidth of $0.2 \mathrm{~nm}$,

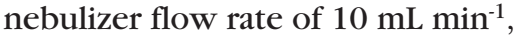
and acetylene flow rate of $1.4 \mathrm{~L} \mathrm{~min}^{-1}$.

\section{Reagents and Standard Solutions}

In this study, all reagents were of analytical reagent grade. The stock standard solutions of Pd(II) (1000 $\mathrm{mg} \mathrm{L}^{-1}$ ) were bought from Merck, Germany. The working standard solutions were made by appropri- ate dilution of the stock solutions. Deionized water was used for the preparation of the solutions. A $0.1 \%$ 2-hydroxy-3-methoxy benzaldehyde thiosemicarbazone (HMBATSC) solution was obtained by dissolving an appropriate amount of HMBATSC (Sigma Aldrich, Germany) in ethanol. The glassware used was washed by soaking overnight in (1:5, v/v) dilute $\mathrm{HNO}_{3}$, then rinsing several times with deionized water.

\section{Synthesis of DESs}

The synthesis of different DESs has been achieved by mixing choline chloride with HBD, such as phenol, urea, and oxalic acid, in different molar ratios into a beaker. The solution was then mixed with a magnetic stirrer at $100{ }^{\circ} \mathrm{C}$ for 30 minutes until a single phase liquid was achieved. Throughout this step, a hydrogen bond was formed with the chlorine of the choline chloride and the hydrogen in the aqueous solution and the formation of DES was achieved.

\section{Procedure}

In this study, $500 \mu \mathrm{L}$ of watermiscible DES used as an extraction solvent was mixed with the standard and sample solution comprising $10 \mu \mathrm{g} \mathrm{L}^{-1}$ (35 mL) of Pd (II), then $400 \mu \mathrm{L}$ of $0.1 \%$ HMBATSC, a complexing agent, was added at $\mathrm{pH}$ 5. Next, $0.8 \mathrm{~mL}$ of THF was added. The DES solvent becomes an aggregate and a turbid solution was achieved. To disperse the combined droplets of the DES into an aqueous phase, the solution was quickly sucked with a needle into a $10 \mathrm{~mL}$ syringe from the centrifuge tube, repeated 10 times. After this step, the Pd(II) becomes extracted into minute DES droplets. The mixture was centrifuged at $4000 \mathrm{rpm}$ for 5 minutes to separate the DES from the aqueous phase. Finally, an aliquot of $100 \mu \mathrm{L}$ of the extract was placed into the home-made microsampler attached to the nebulizer of the flame atomic absorption system and then analyzed (24).

\section{RESULTS AND DISCUSSION}

\section{Selection of Extraction Solvent}

An extracting agent such as the DES must possess certain features such as reduced dissolution in the hydrophilic solution, great extraction affinity to the target metal ion, and easy spreading in water. In the present method, three kinds of HBD with dissimilar molar ratios were added to choline chloride (HBA), such as phenol, oxalic acid, and urea. In all cases, the mixtures were placed into $10 \mathrm{~mL}$ test tubes, capped and stirred for 10 minutes at room temperature, then sonicated for 5 minutes until a DES single liquid phase was achieved.

For the selection of an extracting solvent, $35 \mathrm{~mL}$ of standards/real samples, comprised of $10 \mu \mathrm{g} \mathrm{L}^{-1}$ $\mathrm{Pd}(\mathrm{II})$ at a $\mathrm{pH}$ of 5 and different volumes of DESs used as an extraction solvent, were mixed to obtain the extractant phase with a similar volume. The results showed that the prepared DES from choline chloride:phenol at ( $1: 4)$ ratio was more suitable, and provided the highest extraction efficiency for the analyte ions amongst the other synthesized DESs (shown in Figure 1). The volume of the DES (1:4) eutectic mixture was in the range of 200-700 $\mu \mathrm{L}$, using THF as the emulsifier agent. The effects showed that the extraction efficiency increased by enhancing the volume of the DES from 200 to $500 \mu \mathrm{L}$ (see Figure 2). The highest extraction efficiency was achieved using 500 $\mu \mathrm{L}$ of DES and was chosen as the maximum DES volume for this study.

\section{Effect of $\mathrm{pH}$}

It is known that the $\mathrm{pH}$ value is one of the significant variables disturbing the state of the complexes (as neutral or ion forms) in the sample solution (24). The effect of the $\mathrm{pH}$ on the proposed procedure was 


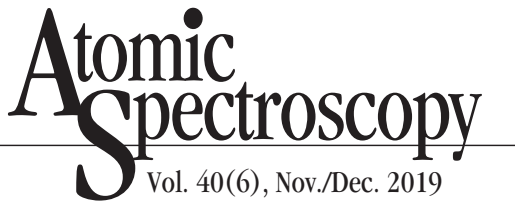

tested in the range of $\mathrm{pH} 2$ to 8 using solutions of phosphate, acetate, borate, and ammonia buffer. Figure 3 shows that the optimum (\%) recovery was achieved in the range of $\mathrm{pH} 4$ to 6 . In extremely acidic conditions, the complex formation was imperfect due to the protonation of the complexing agent, and while enhancing the $\mathrm{pH}$, it initiated a steady reduction in extraction efficiency of the analyte which may be due to the precipitation of palladium hydroxide. Hence, $\mathrm{pH} 5$ was chosen for additional studies.
Effect of Complexing Agent

The non-polar complexing agent HMBATSC can freely synthesize complexes with Pd(II) both in real samples and certified standards (25). In the present study, Pd(II) was complexed with $0.1 \%$ of HMBATSC in the range of 100 to $500 \mu \mathrm{L}$ (see Figure 4). Optimum (\%) recoveries of the analytes was achieved using $400 \mu \mathrm{L}$ of $0.1 \%$ HMBATSC. A further increase in ligand volume did not effect the (\%) recovery of the analyte. A slight reduction of extraction efficiency at high levels of HMBATSC was observed which was due to an excess of concentration of the ligand molecules trapped in the micelles. Thus, $400 \mu \mathrm{L}$ was chosen as a maximum complexing agent level for further work.

Effect of Number of Rapid Extraction Cycles

In this work, the process of extraction involved mixing of the standard/sample solution and extraction solvent using a number of rapid cycles (uptaking and dispensing) into a syringe of $10 \mathrm{~mL}$,

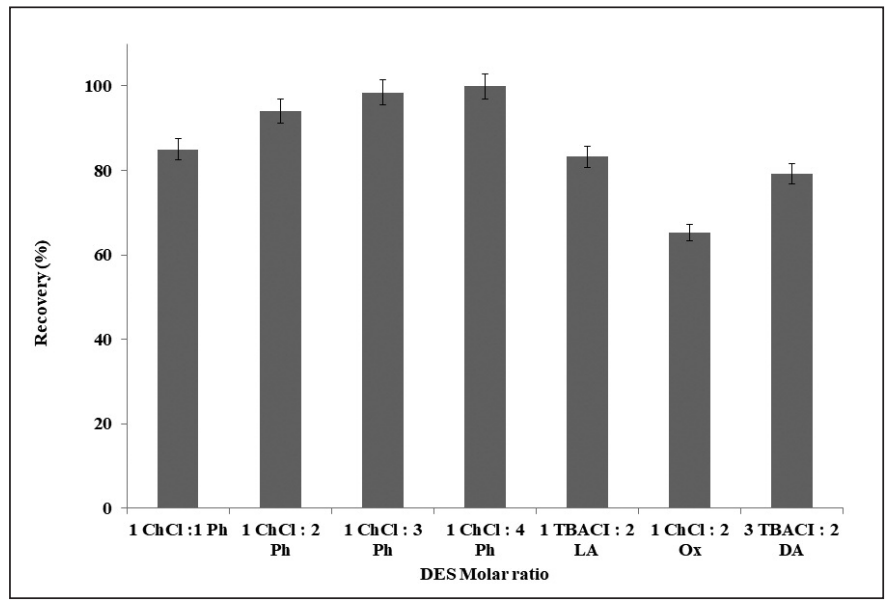

Fig. 1. Effect of compositions of DESs on the recovery of $P d$ (II). Conditions $10 \mu \mathrm{g} \mathrm{L}^{-1} \mathrm{Pd}(\mathrm{II}),(\mathrm{pH}$ 5), HMBATSC (O.1\% $m / v) 400 \mu \mathrm{L}$, volume of ChCl:Ph (1:4); $500 \mu \mathrm{L}$, THF $800 \mu \mathrm{L}$.

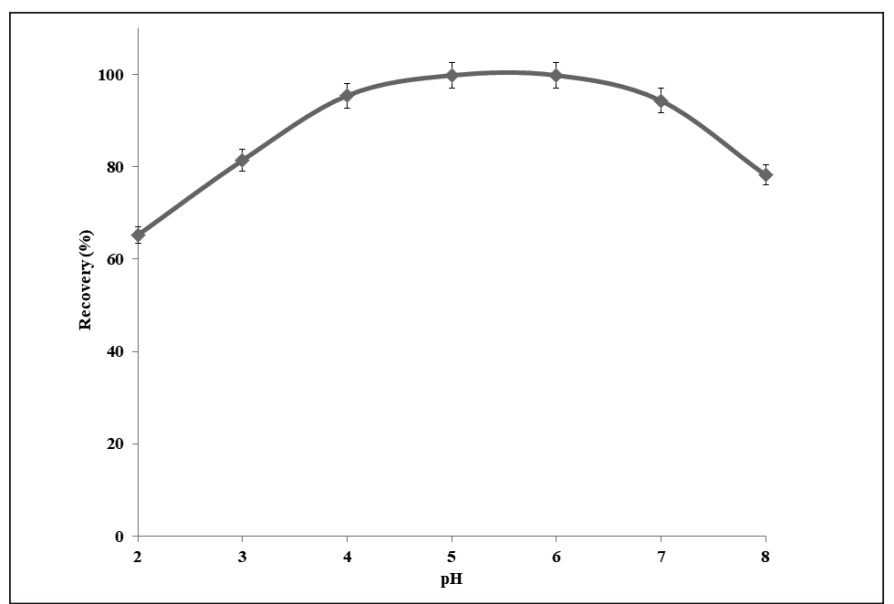

Fig. 3. Effect of $p H$ on the recovery of Pd(II). Conditions 10 $\mu g L^{-1} P d(I I)$, HMBATSC $(0.1 \% \mathrm{~m} / v) 400 \mu \mathrm{L}$, volume of ChCl:Pb (1:4); $500 \mu L, T H F 800 \mu L$.

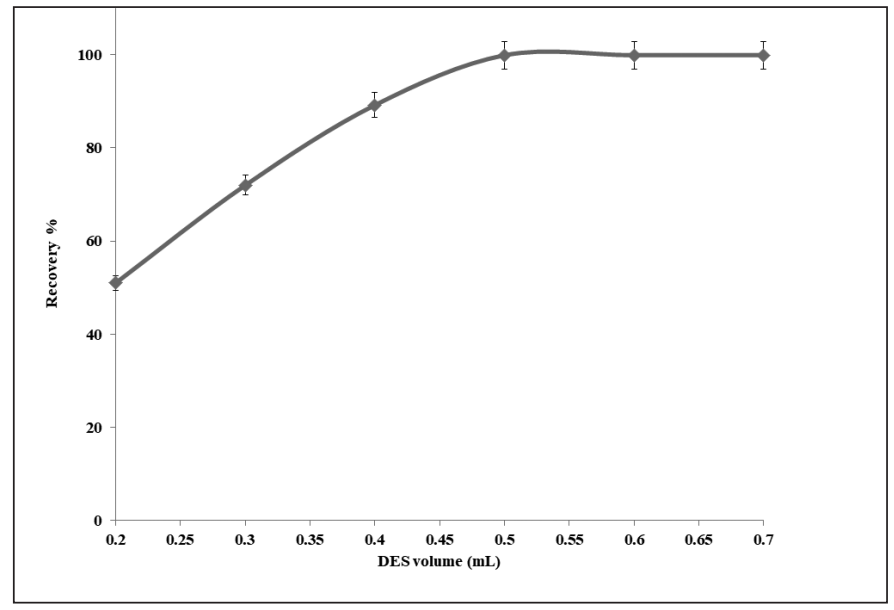

Fig. 2. Effect of the volume of DES (1:4) on the recovery of Pd (II). Conditions: $10 \mu \mathrm{g} \mathrm{L} \mathrm{L}^{-1}$ of Pd (II), buffer $2 \mathrm{~mL}(\mathrm{pH}$ 5), HMBATSC $(0.1 \% \mathrm{~m} / v) 400 \mu \mathrm{l}$, THF $500 \mu \mathrm{L}$.

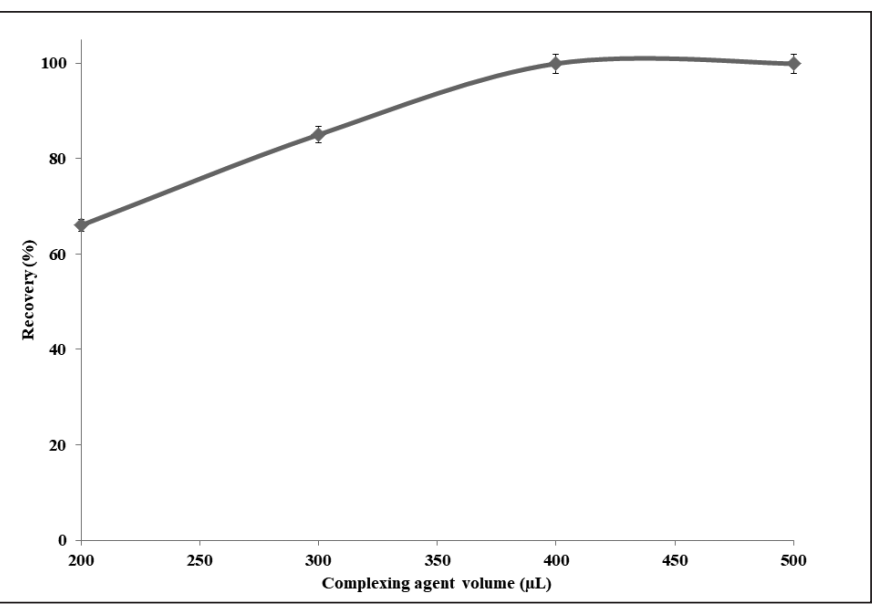

Fig. 4. Effect of the volume of HMBATSC $(0.1 \% \mathrm{~m} / \mathrm{v})$ on the recovery of Pd(II). Conditions: $10 \mu \mathrm{g} L^{-1} P d(I I)$, buffer $2 \mathrm{~mL}$ ( $\mathrm{pH}$ 5), volume of ChCl:Ph (1:3); $500 \mu \mathrm{L}, \mathrm{THF} 800 \mu \mathrm{L}$. 
followed by injection into the centrifuge tube. The number of cycles was defined as the extraction number/time. Hence, the act of simply pulling and pushing the syringe was carried out to completely disperse the aggregated droplets of DES into the aqueous phase. For increasing the extraction efficiency of the analyte, the number of cycles of pulling and pushing was studied from 2 to 10 times. The results in Figure 5 show that by increasing the number of cycles had an effect on the extraction efficiency. It can be seen that after 8 cycles, the extraction efficiency reached optimum level, and remained constant as more cycles were performed. However, 8 cycles was chosen as the maximum number for further work.

\section{Effect of THF Volume}

By mixing an aprotic solvent such as THF, the process of selfaggregation of the DESs from the aqueous phase occurs. The addition of THF into the single aqueous phase/DES solution reduces the contact of water to DES. Thereafter, the droplets of DES might leave the molecules of water and an immiscible and self-aggregate liquid becomes detached. The most rational and self-aggregation credible
DES mechanisms includes $\pi-\pi$ overlap amongst the ring of aromatic compounds, $\mathrm{H}$ bonding amongst functional groups of the DESs, and other interactions of transfer of charge (26).

The volume of the extractant phase depends on the volume of the emulsifier solvent. The effect of THF volume was examined from 300 to $1000 \mu \mathrm{L}$. The outcome indicated that by increasing the THF volume to $800 \mu \mathrm{L}$, the extraction efficiency of the analyte improved and remained constant as its volume increased further. This also increased the extractant phase volume. By enhancing the THF volume, the solubility of the target analyte increased in the aqueous solution and reduced the (\%) recovery. When a lower volume of 300 $\mu \mathrm{L}$ of THF was used, no turbidity was observed in the solution. Thus, $800 \mu \mathrm{L}$ was chosen as the maximum THF volume.

\section{Selectivity}

In order to establish the developed DES-AA-ELLME method selective for the measurement of Pd(II), the effects of interfering ions typically found in environmental samples were assessed. This was achieved by analyzing $10 \mathrm{~mL}$ of

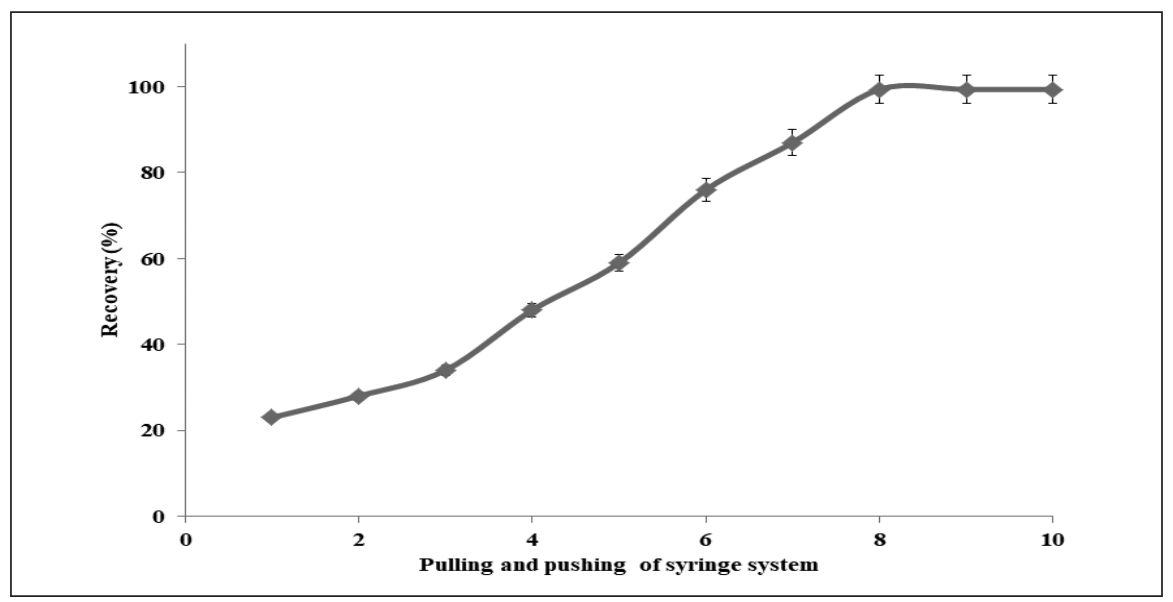

Fig. 5. Effect of the pulling and pushing of syringe as air assisted on the recovery of Pd (II). Conditions: $10 \mu g L^{-1}$ Pd(II), buffer $2 \mathrm{~mL}(\mathrm{pH} 5), \mathrm{HMBATSC}(0.1 \% \mathrm{~m} / \mathrm{v})$ $400 \mu \mathrm{L}$, volume of ChCl:Ph (1:4); $500 \mu \mathrm{L}, \mathrm{THF} 800 \mu \mathrm{L}$.

$10 \mu \mathrm{g} \mathrm{L}^{-1}$ of Pd(II) solution containing interfering ions at dissimilar levels according to the suggested extraction method. An added foreign species was created to interfere, i.e., to see if it caused $\pm 5 \%$ difference in the AAS signal. The results indicated that with 15,000 $\mu \mathrm{g} \mathrm{mL} \mathrm{m}^{-1}$ of $\mathrm{Cl}^{-}, 5000 \mu \mathrm{g} \mathrm{mL} \mathrm{m}^{-1}$ of $\mathrm{K}^{+}$, $\mathrm{Na}^{+}, \mathrm{NO}_{3}{ }^{-}, \mathrm{PO}_{4}{ }^{3-}$ and $\mathrm{SO}_{4}{ }^{2-}, 2000$

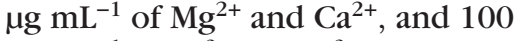
$\mu \mathrm{g} \mathrm{mL} \mathrm{m}^{-1}$ of $\mathrm{As}^{3+}$ and $\mathrm{Al}^{3+}$ there are no outstanding interferences in the measurement of Pd(II). The ions $\mathrm{Co}^{2+}, \mathrm{Cu}^{2+}, \mathrm{Cd}^{2+}, \mathrm{Ni}^{2+}, \mathrm{Mn}^{2+}, \mathrm{Zn}^{2+}$, and $\mathrm{Pb}^{2+}$ could be tolerated up to $50 \mu \mathrm{g} \mathrm{mL}{ }^{-1}, \mathrm{Fe}^{3+}$ to $25 \mu \mathrm{g} \mathrm{mL}{ }^{-1}$, whereas $\mathrm{Cr}^{3+}$ could be tolerated up to $25 \mu \mathrm{g} \mathrm{mL} \mathrm{mL}^{-1}$. It was observed that the proposed method can be efficiently applied to the analysis of environmental/biological samples.

\section{Analytical Performance}

The limits of quantification (LOQ) and limits of detection (LOD) for the established analytical method were calculated from equation $10 \mathrm{~s} / \mathrm{m}$ and $3 \mathrm{~s} / \mathrm{m}$, respectively, where 's' denotes 10 standard deviations of 10 blank solutions, and ' $m$ ' represents the slope of the calibration curve. The LOQ and LOD were measured at $1.2 \mu \mathrm{g} \mathrm{L^{-1 }}$ and $4.0 \mu \mathrm{g} \mathrm{L}^{-1}$, respectively. Reproducibility and repeatability of the proposed method was measured as (\%) relative standard deviation, observed at 3.6\%. The linear range of the developed method was 4-500 $\mu \mathrm{g} \mathrm{L}^{-1}$ with a correlation coefficient of $\left(r^{2}\right) 0.999$. The preconcentration factor (PF) was found to be 70 for $35 \mathrm{~mL}$ of sample volume, reduced to a $0.5 \mathrm{~mL}$ final volume.

The developed DES-AA-ELLME method was applied to the measurement of Pd(II) ions in different types of water samples (tap, mineral, river, and seawater) $(n=6)$ (Table I). The standard addition method was applied to the water samples, and quantitative recovery values were observed. The accu- 
racy of the DES-AA-ELLME method was confirmed with certified referlyst (National Institute of Standards ery of $98.8 \%$ (see Table II). The developed method was applied to road dust, tunnel dust, and a catalytic con-verter (exhaust emission control device that reduces toxic gases) after the sample pretreatment procedure (27). The results are given in Table II. A comparison ture values is provided in Table III.

\section{CONCLUSION}

An innovative method, the deep eutectic solvent-based air-assisted emulsion liquid-liquid microextraction coupled with FAAS, was developed for the determination of Pd(II) in water and environmental samples. A novel polar DES was prepared by mixing HBD with quaternary ammonium salt (choline chloride phenol). THF was mixed into a single phase solution, which resulted in a turbid solution. Air ence material NIST SRM 2557 Cataand Technology, USA) with a recovof the present method with litera- was introduced into the tubes with the help of a syringe to improve the rapid formation of small droplets in the aqueous solution and the surface interaction among non-polar and polar liquids. Due to this action, the turbidity of the solution increased. The main benefits of this technique are short extraction time, eliminates the use of chlorinated extraction solvents, results in low cost and simple application. The developed DES-AA-ELLME method offers a high preconcentration factor, low detection limits, and extended linear range. The tolerance limits of the interfering ions are very high. Thus, the present method can be successfully applied to highly saline and very complex matrixes, and avoids producing toxic waste.

\section{ACKNOWLEDGMENT}

Abdul Haleem Panhwar is very thankful to TUBITAK for providing the financial support.

$\overline{\text { Received May 11, } 2019 .}$

\section{REFERENCES}

1. S.P.S. Spoehrle, T.H. West, J.E. Taylor, A.M. Slawin, A.D. Smith, J. Am. Chem. Soc. 139, 11895 (2017).

2. M. Zhao, K. Deng, L. He, Y. Liu, G. Li, H. Zhao, Z. Tang, J. Am. Chem. Soc. 136,1738 (2014).

3. B. Majidi, F. Shemirani, Talanta 93, 245 (2012).

4. E. Yavuz, S. Tokalıoglu, H. Sahan, S. Patat, Talanta 128, 31 (2014).

5. J. Kielhorn, C. Melber, D. Keller, I. Mangelsdorf, Int J Hyg Environ Health 205, 417 (2002).

6. P. Liang, E. Zhao, F. Li, Talanta 77, 1854 (2009).

7. B. Godlewska-Zyłkiewicz, Microchim. Acta 147, 189 (2004).

8. O. Ortet, A.P. Paiva, Sep. Purif. Technol. 156, 363 (2015).

9. Z. Es'haghi, F. Moeinpour, Ir. J. Anal. Chem 1, 58 (2014).

10. T. Suoranta, O. Zugazua, M. Niemelä, P. Perämäki, Hydrometallurgy 154, 56 (2015).

11. J. Fang, L.-W. Liu, X.-P. Yan, Spectrochim. Acta B.: Atomic Spectroscopy 61, 864 (2006).

12. N. Shokoufi, F. Shemirani, Y. Assadi, Anal. Chim. Acta 597, 349 (2007).

TABLE II

Determination of Pd(II) in Real Water Samples

After Application of DES-AA-ELLME and Standard Addition Method, N=4

\begin{tabular}{lccc}
\hline Sample & $\begin{array}{c}\text { Added } \\
\left(\mu \mathrm{g} \mathrm{L}^{-1}\right)\end{array}$ & $\begin{array}{c}\text { Found } \\
\left(\mu \mathrm{g} \mathrm{L}^{-1}\right)\end{array}$ & $\begin{array}{c}\text { Recovery } \\
(\%)\end{array}$ \\
\hline Tap water & 0 & $\mathrm{BDL}$ & - \\
& 20 & $19.8 \pm 1.2^{\mathrm{a}}$ & $99 \pm 2$ \\
Mineral water & 0 & $49.2 \pm 2.4$ & $98 \pm 3$ \\
& 20 & $\mathrm{BDL}$ & - \\
River water & 0 & $19.9 \pm 1.3$ & $99 \pm 2$ \\
& 20 & $49.0 \pm 2.1$ & $98 \pm 4$ \\
Seawater & 50 & $19.7 \pm 1.5$ & $98 \pm 3$ \\
& 0 & $48.7 \pm 2.6$ & $97 \pm 4$ \\
& 20 & $\mathrm{BDL}$ & - \\
& 50 & $19.8 \pm 1.4$ & $99 \pm 3$ \\
& & $49.4 \pm 1.9$ & $99 \pm 3$ \\
\hline
\end{tabular}

BDL: Below detection limit.

${ }^{\mathrm{a}}$ mean $\pm \mathrm{SD}$.
Measurement of Pd(II) in SRM and Environmental Samples After Application of DES-AA-ELLME, N=4

\begin{tabular}{lccc}
\hline SRM & $\begin{array}{c}\text { Certified } \\
\text { Value } \\
\left(\mu \mathrm{g} \mathrm{L}^{-1}\right)\end{array}$ & $\begin{array}{c}\text { Obtained } \\
\text { Value } \\
\left(\mu \mathrm{g} \mathrm{L}^{-1}\right)\end{array}$ & $\begin{array}{c}\text { Recovery } \\
(\%)\end{array}$ \\
\hline $\begin{array}{l}\text { NIST SRM 2557 } \\
\text { Catalyst }\end{array}$ & $233.2 \pm 1.9$ & $230.5 \pm 7.4^{\mathrm{a}}$ & 98.8 \\
\hline Sample & $\begin{array}{c}\text { Found } \\
\left(\mu \mathrm{g} \mathrm{g}^{-1}\right)\end{array}$ \\
\hline Catalytic converter 1 & $1202 \pm 26$ \\
Catalytic converter 2 & $1134 \pm 23$ \\
Catalytic converter 3 & $1452 \pm 27$ \\
Road dust & $0.16 \pm 0.02$ \\
Tunnel dust & $0.29 \pm 0.03$ \\
\hline
\end{tabular}

${ }^{\mathrm{a}}$ mean $\pm \mathrm{SD}$. 
TABLE III

Comparison of Developed Method With Other Reported Methods for Pd(II)

\begin{tabular}{|c|c|c|c|c|c|c|c|}
\hline $\begin{array}{l}\text { Enrichment } \\
\text { Method }\end{array}$ & $\begin{array}{c}\text { Detection } \\
\text { System }\end{array}$ & $\begin{array}{l}\text { Preconcen- } \\
\text { tration } \\
\text { Factor }\end{array}$ & $\begin{array}{c}\text { Detection } \\
\text { Limit } \\
\left(\mu \mathrm{g} \mathrm{L}^{-1}\right)\end{array}$ & $\begin{array}{l}\text { RSD } \\
(\%)\end{array}$ & $\begin{array}{r}\text { Linearity } \\
\left(\mu \mathrm{g} \mathrm{L}^{-1}\right)\end{array}$ & $\begin{array}{l}\text { Time } \\
\text { (min) }\end{array}$ & Reference \\
\hline Coprecipitation & FAAS & 25 & 1.5 & - & - & $>30$ & $(27)$ \\
\hline SPE & FAAS & 60 & 1.5 & 2.4 & - & $>15$ & (28) \\
\hline $\mathrm{CPE}$ & GFAAS & 8.7 & 2.0 & - & - & $>15$ & (29) \\
\hline SFODME & FAAS & 49.9 & 0.60 & 2 & $2-400$ & $>10$ & (31) \\
\hline DLLME & FAAS & 45.7 & 90 & 0.7 & $100-2000$ & $>10$ & (32) \\
\hline DES-AA-ELLME & FAAS & 70 & 1.2 & 3.6 & $4-500$ & 7 & Present work \\
\hline
\end{tabular}

SPE: Solid phase extraction, CPE: Cloud point extraction,

DLLME: Dispersive liquid liquid microextraction,

SFODME: Solidified floating organic drop microextraction,

DES-AA-ELLME: Deep eutectic solvent based air-assisted emulsification liquid-liquid microextraction,

FAAS: Flame atomic absorption spectrometry,

GFAAS: Graphite furnace atomic absorption spectrometry,

RSD: Relative standard deviation.

13. E. Psillakis, N. Kalogerakis, TrAC Trends Anal. Chem. 22, 565 (2003).

14. K. Wrobel, S. Kannamkumarath, K. Wrobel, J.A. Caruso, Green Chem. 5, 250 (2003).

15. S. Garrigues, S. Armenta, M. de la Guardia, Encyclopedia of Inorganic and Bioinorganic Chemistry (2016).https://doi.org/10.1002/97 81119951438.eibc2426

16. N.S. La Colla, C.E. Domini, J.E. Marcovecchio, S.E. Botté, J. Environ. Manage. 151, 44 (2015).

17. C. Lin, China Nonferrous Metallurgy 2, 29 (2016)

18. J. Ye, S. Liu, M. Tian, W. Li, B. Hu, W. Zhou, Q. Jia, Talanta 118, 231 (2014).

19. F. Heydari, M. Ramezani, Sep. Sci. Technol.165, 27 (2017).

20. B. Peng, Y. Shen, Z. Gao, M. Zhou, Y. Ma, S. Zhao, Food Chem. 176, 288 (2015).

21. G. Baccolo, M. Clemenza, B. Delmonte, N. Maffezzoli, M. Nastasi, E. Previtali, M. Prata, A. Salvini, V. Maggi, Anal. Chim. Acta 922, 11 (2016).

22. S. Chen, X. Zhu, Miner. Eng. 23,
1152 (2010).

23. B. Barfi, A. Asghari, M. Rajabi, A.G. Moghadam, N. Mirkhani, F. Ahmadi, J. Pharm. Biomed. Anal. 111, 297 (2015).

24. S. Sacmaci, S. Kartal, Talanta 109 , 26 (2013).

25. I. Srivani, A. Praveen Kumar, P.R. Reddy, K. Reddy, V.K. Reddy, Annali di Chimica 97, 1237 (2007).

26. Y. Dai, J. van Spronsen, G.-J. Witkamp, R. Verpoorte, Y.H. Choi, Anal. Chim. Acta 766, 61 (2013).

27. M. Soylak, M. Tuzen, J. Hazard. Mater. 152, 656 (2008).

28. R. Praveen, S. Daniel, T.P. Rao, S. Sampath, K.S. Rao, Talanta 70, 437 (2006).

29. C.B. Ojeda, F.S. Rojas, J.M.C. Pavón, Microchim. Acta 158, 103 (2007).

30. M. Pouyan, G. Bagherian, N. Goudarzi, Microchem. J. 127, 46 (2016).

31. M. Mohamadi, A. Mostafavi, Talanta 81, 309 (2010).

32. T.A. Kokya, K. Farhadi, J. Hazard. Mater. 169, 726 (2009). 